\title{
STUDY OF CHITINASE AND CHITINOLYTIC ACTIVITY OF LACTOBACILLUS STRAINS
}

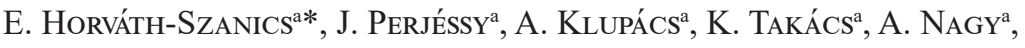 \\ E. KoppánY-SZABÓa ${ }^{a}$, F. HegYI ${ }^{\mathrm{a}}$, E. NÉMETH-SZERDAHELYI ${ }^{\mathrm{a}}$, M.Y. DU ${ }^{\mathrm{b}, c}$, Z.R. WANG ${ }^{\mathrm{b}}$, \\ J.Q. KAN ${ }^{b, c}$, and Zs. ZALÁN ${ }^{\mathrm{a}, \mathrm{c}}$ \\ ${ }^{\text {a} F o o d ~ S c i e n c e ~ R e s e a r c h ~ I n s t i t u t e ~ o f ~ N a t i o n a l ~ A g r i c u l t u r a l ~ R e s e a r c h ~ a n d ~ I n n o v a t i o n ~ C e n t r e, ~ H-1022 ~ B u d a p e s t, ~}$ \\ Herman Ottó út 15. Hungary \\ ${ }^{\mathrm{b}}$ College of Food Science, Southwest University, No. 2 Tiansheng Road, Beibei District, Chongqing 400715. P.R. \\ China \\ ${ }^{\mathrm{c} C h i n e s e-H u n g a r i a n}$ Cooperative Research Centre of Food Science, Food Science Research Institute, \\ H-1022 Budapest, Herman Ottó út 15. Hungary
}

(Received: 13 December 2019; accepted: 4 March 2020)

\begin{abstract}
The increasing consumer demand for less processed and more natural food products - while improving those products' quality, safety, and shelf-life - has raised the necessity of chemical preservative replacement. Biopreservation refers to extended storage life and enhanced safety of foods using the natural microflora and (or) their antibacterial products. Chitinolytic enzymes are of biotechnological interest, since their substrate, chitin, is a major structural component of the cell wall of fungi, which are the main cause of the spoilage of food and raw plant material. Among the several organisms, many bacteria produce chitinolytic enzymes, however, this behaviour is not general. The chitinase activity of the lactic acid bacteria is scarcely known and studied.

The aim of the present study was to select Lactobacillus strains that have genes encoding chitinase, furthermore, to detect expressed enzymes and to characterise their chitinase activity. Taking into consideration the importance of chitin-bindig proteins (CBPs) in the chitinase activity, CBPs were also examined. Five Lactobacillus strains out of 43 strains from 12 different species were selected by their chitinase coding gene. The presence of the chitinase and chitin-biding protein production were confirmed, however, no chitinolytic activity has been identified.

Keywords: chitinase-coding genes, chitinase, chitinase-like proteins, chitin-binding proteins, Lactobacillus
\end{abstract}

Biocontrol by lactic acid bacteria (LAB) is currently the principal alternative to preservatives in food (RAmos et al., 2016), and is widely studied because of the role and long history of use of LAB in fermented foods, their ability to produce antifungal metabolites (e.g. organic acids, hydrogen peroxide, diacetyl, bacteriocins), and their Generally Recognized as Safe (GRAS) and Qualified Presumption of Safety (QPS) status in the USA and EU (BEHERA et al., 2018). Lactic acid bacteria are safe to consume and during the processing they naturally dominate the microflora of many fermented foods.

Among spoilage microorganisms, fungi are major issue at any stage of the food chain from the postharvest storage of raw material till the end consumption of the processed foods, because of their ability to produce spores and grow in different and even harsh environments. Biological control strategy involving microbial enzymes may address preservation of foods from fungal attack. The hydrolases and the oxidoreductases are playing relevant role in this regard. Cell walls of microorganisms act as the substrates for the hydrolases. Most of fungal cell wall hydrolases have chitinolytic activity.

\footnotetext{
* To whom correspondence should be addressed.

Phone: +36 (1) 796-0400; e-mail: szanics.eniko@eki.naik.hu
} 
Bacterial chitinases generally consist of multiple functional domains such as: cathalytic domain, chitin-binding domain, and non-cathalytic domain (MANJEET et al., 2013). The chitin-binding domain (CBD or chitin-binding module, $\mathrm{CBM}$ ) helps in binding to insoluble chitin and increases substrate accessibility, CBMs may also occur as individual chitin-binding proteins (CBPs) without chitinase activity. Chitinases often work synergistically with these chitin-binding proteins (CBPs), which bind to the insoluble crystalline chitin, leading to structural changes and attaching the bacteria to the substrate and promoting the degradative actions of chitinases.

The LAB are widespread in the nature, but their ability to catabolise polisaccharides, as chitin, has not been extensively studied. LEISNER and co-workers (2008) have studied 115 strains from 29 species from the lactic acid bacteria group, among others from the genera Carnobacterium, Lactobacillus, Leuconostoc, and Weissella, and found chitinase activity by strains of only two Carnobacterium species. BECK and co-workers (2009) investigated the cell surface proteins of the Lactobacillus plantarum 299v probiotic bacterium. Based on the resulting peptide masses, the authors identified, among other proteins, a chitin-binding protein.

The present study focused on isolating and selecting chitinase producing LAB by the investigation of the genes encoding chitinases and the detection of the chitinase expression and their activity.

\section{Materials and methods}

\subsection{Microorganisms}

More than 40 strains, belonging to the Lactobacillus (L.) genera (strains from different species, eg. acidophilus, casei, curvatus, delbrueckii, fermentum, rhamnosus, pentosus, plantarum, and sakei), were investigated. They were selected from different sources, both from strain collections and also isolated from fermented foods in which LAB play an essential role, namely yoghurt, kimchi, and olive. Microorganisms from natural chitin-rich environment, mushrooms and insects, were also collected. For positive control a Serratia (S.) marcescens CSM-RMT-1 (grateful thanks to the Microbiology and Biotechnology Department of Faculty of Food Science, SZIU) strain was used. For negative control both for Lactobacillus indentification and also for the chitinase activity Pseudomonas aeruginosa B 01687, Bacillus cereus ATCC 10702, and B. licheniformis ATCC 14580 strains were used.

\subsection{Investigation of the presence of a chitinase coding gene}

1.2.1. Bacterial DNA extraction. Bacteria were proliferated in de Man-Rogosa-Sharpe (MRS) broth, and then washed with $0.9 \%$ normal saline. The bacterial cell wall was digested at $37{ }^{\circ} \mathrm{C}$ for $30 \mathrm{~min}$ using lysozyme enzyme. Bacterial DNA extraction was performed according to the Wizard ${ }^{\circledR}$ DNA Clean-up System (Promega, Madison, Wisconsin, USA). The concentration and the purity of the isolated DNA were determined with Colibri instrument (Titertek-Berthold, Berthold Detection Systems GmbH, Pforzheim, Germany).

1.2.2. Identification of Lactobacillus species. In order to confirm that bacteria belong to Lactobacillus genus we applied a DNA based molecular biological method using Lactobacillus primer pairs IFL (5'-AGAAGAGGACAGTGGAAC-3') and IFR (5'-TTACAAACTCT CATGGTGTG-3') designed by SinGH and RAMESH (2008). PCR reactions were performed in 
3 parallel measurements accomplished using a Biometra TOne (Analytik Jena AG, Jena, Germany) gradient PCR instrument.

1.2.3. Detection of chitinase gene. The presence of the chitinase gene was detected by using two different primer pairs. First, PCR amplification was performed according to LEISNER and co-workers (2008) using chiAF (5'-ACCCTTCCCACTTTCAAGCC-3') and chiAR (5'-ATATGAGCGTCAGCTCCTCC-3') primers derived from the L. lactis subsp. lactis IL1403 chiA gene. Then chiFEMSF (5'-GATATCGACTGGGAGTTCCC-3') and chiFEMSR ( 5 '-CATAGAAGTCGTAGGTCATC-3') primers designed by RAMAIAH and coworkers (2000) were applied. These primer pairs were designed for PCR amplification of chiA gene fragments by alignment and selection of highly conserved regions of several chiA genes from different microorganism sequences (GenBank accession numbers are: $S$. marcescens X03657, Z36294; Alteromonas sp., D13762; B. circulans, M57601, and Aeromonas caviae, U09139). PCR results were evaluated by a FlashGel TM (Lonza Group Ltd.) electrophoresis device.

\subsection{Identification of chitinase and chitinase homologous proteins by immunoblot and HPLC techniques}

1.3.1. SDS-PAGE and Western blots. One of the representative peptide sequences of the chitinase enzyme protein originating from Trichoderma hamatum, posteriorly named as Thamchi peptide (20-mer, Mw: 2276 Da: Lys Ala Asn Arg Asn Leu Lys Val Met Leu Ser Ile Gly Gly Trp Thr Trp Ser Thr Asn), was sequenced and used as antigen to produce polyclonal antibody in rabbit. The Thamchi peptide-specific polyclonal antibody was prepared by subcutaneous immunisation in Hungarian wild rabbits and purified to $\operatorname{IgG}$ antibodies. The electrophoretic separation was performed using a $4 \%$ stacking gel and a $12 \%$ resolving gel. After electrophoresis, gels were either stained with Coomassie brillant blue or electrophoretically transferred to PVDF membranes. The immune-reactive proteins were identified by immunblot technique using Thamchi peptide-specific rabbit IgG serum.

1.3.2. High-performance liquid chromatography (HPLC). Supernatants of S. marcescens and L. acidophilus N2 and purified chitinase (Streptomyces griseus, Sigma) used as standards were injected on a C18 column $\left(4.6 \times 250 \mathrm{~mm}\right.$, Jupiter ${ }^{\circledR} 300-5$, Phenomenex $)$ in a HPLC system (Shimadzu LC-20AD - DG-20A using ECOM Flash 14 DAD UV detector). The separation was performed according to the method of LE BouRSE and co-workers (2011).

\subsection{Chitin-binding protein (CBP)}

1.4.1. Extraction of cell surface proteins. Cell surface proteins were extracted according to BECK and co-workers (2009) with minor modification. Selected strains were grown on MRS medium for two days and then centrifuged (4300 r.p.m., $15 \mathrm{~min}$ ). The precipitate was washed with $1 \mathrm{ml}$ PBS and then centrifuged again (6000 r.p.m., $10 \mathrm{~min})$. The precipitate was suspended in $1 \mathrm{ml}$ of $0.2 \%$ CHAPS (3-[(3-Cholamidopropyl) dimethylammonio]-1propanesulfonate) in PBS and stirred for $1 \mathrm{~h}$. After centrifugation (8000 r.p.m., $20 \mathrm{~min}$ ), the supernatant was used for further assays.

1.4.2. CBP assay. The chitin-binding proteins were separated according to INOUE and co-workers (2001) with minor modifications. Six Lactobacillus strains were cultured for two days at $37{ }^{\circ} \mathrm{C}$ in MRS medium and centrifuged (14 000 r.p.m., 5 min). One and a half millilitres of the supernatant was added and shaked for 1 hour at room temperature. After 
extraction, the solution was centrifuged (14 000 r.p.m., 5 min). The precipitate was washed four times with physiological saline solution and centrifuged (14 000 r.p.m., 5 min). After centrifugation the precipitate was analysed by SDS-PAGE.

\subsection{Determination of chitinase activity}

1.5.1. Microbiological method. Chitinolytic activity of Lactobacillus strains was investigated according to LEISNER and co-workers (2008) on basic chitin medium (BCM) (tryptone 1\% $(\mathrm{w} / \mathrm{v})$, yeast extract $0.5 \%(\mathrm{w} / \mathrm{v}), \mathrm{NaCl} 1 \%(\mathrm{w} / \mathrm{v})$, agar $1.5 \%(\mathrm{w} / \mathrm{v})$, and chitin $0.25 \%(\mathrm{crab}$ shell). Cell suspension aliquots $(20 \mu \mathrm{l})$ were dropped onto the surfce of BCM agar and incubated at $30{ }^{\circ} \mathrm{C}$ for up to 1 week, the presence of clearing zones around colony indicates chitinase activity. This study was done with colloidal chitin (prepared according to LIU and co-workers (2014)) also instead of crude chitin, since the colloidal chitin is more soluble and accessible, induces chitinase production, and it is hidrolised by bacterial chitinases more rapidly.

1.5.2. Chitin azure chitinase assay. In this study, chitinase activity was determined by spectrophotometry according to the method of THOMPSON and co-workers (2001) using chitin azure (CA), chitin covalently coupled with the Remazol brillant violat 5R dye, as substrate. One enzyme unit was defined as a change in the optical density at $570 \mathrm{~nm}\left(\Delta \mathrm{OD}_{570}\right)$ of $1.0 \mathrm{in}$ $24 \mathrm{~h}$.

\section{Results and discussion}

\subsection{Detection of chitinase gene}

2.1.1. Identification of Lactobacillus sp. by PCR-techniques. The results of PCR reactions with Lactobacillus specific IFL-IFR primer pairs show that non-Lactobacillus bacteria gave no or only a slight signal, whereas all Lactobacillus from the strain collection gave strong signals. PCR amplification of bacterial strains isolated from food samples gave strong fragment band except for only one sample, so these strains belong to the Lactobacillus genus also.

2.1.2. Detection of chitinase gene. Our results show that we could get strong, $119 \mathrm{bp}$ amplified fragments by the adapted chiAF/chiAR primer pair in case of two microorganisms (L. acidophilus N2, L. delbrueckii subsp. bulgaricus B397), which means that these samples hold the chitinase gene. At the same time, slight fragment-bands could be detected due to inadequate primer binding or the presence of other chitinase gene haplotypes (Fig. 1).

In case of the control S. marcescens, $225 \mathrm{bp}$ length fragment band amplified by the adapted chiFEMSF / chiFEMSR primer was obtained. Contrarily, in our experiments with the 41 Lactobacillus strains, only many non-specific fragment bands were amplified, so we concluded that the chiFEMSF / chiFEMSR primer pair is not suitable for the identification of Lactobacillus chitinase gene (Fig. 2). The detected chitinase gene from the Serratia strain is not equal (at least in nucleotide composition) to the chitinase gene identified in the Lactobacillus strains by chiAF / chiAR primers (Fig. 3). The presence of chitinase-coding genes in Lactobacillus strains has been a less researched field as the occurrence of the chitinase gene in Lactobacillus strain is very rare, not so characteristic. 


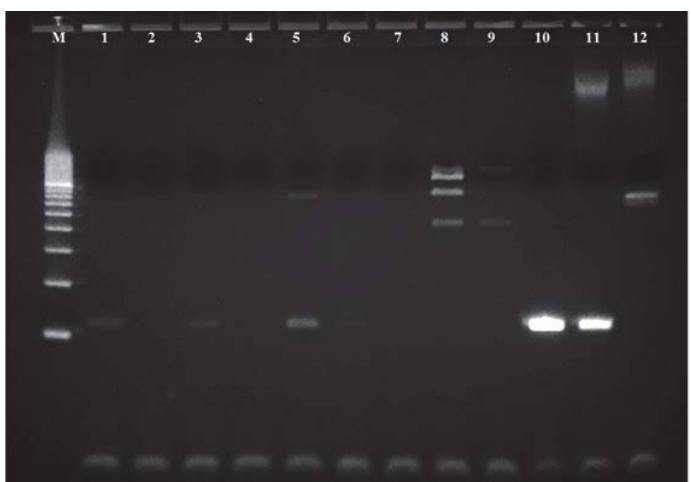

Fig. 1. PCR results using ChiA primer pair: M: DNA marker; 1: Lactobacillus sp. 2231; 2: L. pentosus 1727; 3: L. sakei subsp. sakei 2471; 4: L. plantarum 2391; 5: L. buchneri 1145; 6: P. aeruginosa; 7: B. cereus; 8: B. licheniformis 1/1 $10 \mathrm{ng} / \mu \mathrm{l}$; 9: B. licheniformis $1 / 220 \mathrm{ng} / \mu \mathrm{l}$; 10: L. acidophilus $\mathrm{N}$; 11: L. delbrueckii subsp. bulgaricus B397; 12: L. plantarum 2142

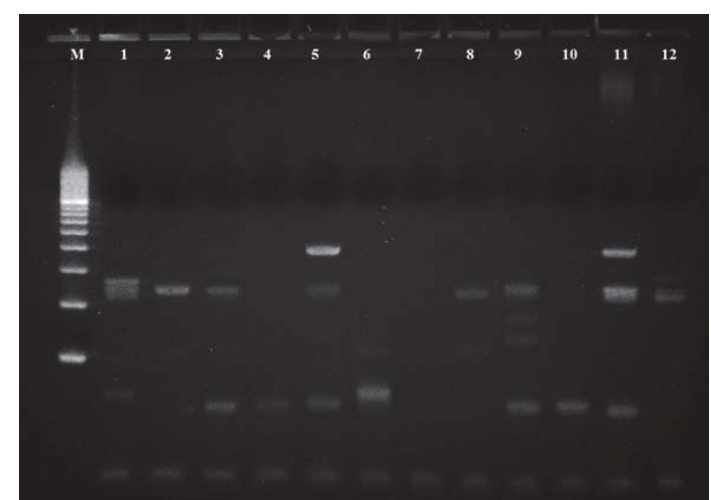

Fig. 2. PCR results using ChiFEM primer pair: M: DNA marker; 1: Lactobacillus sp. 2231; 2: L. pentosus 1727; 3 : L. sakei subsp. sakei 2471; 4: L. plantarum 2391; 5: L. buchneri 1145; 6: P. aeruginosa; 7: B. cereus; 8: B. licheniformis $1 / 110 \mathrm{ng} / \mu \mathrm{l}$; 9: B. licheniformis $1 / 220 \mathrm{ng} / \mu \mathrm{l}$; 10: L. acidophilus $\mathrm{N} 2$; 11: L. delbrueckii subsp. bulgaricus B397; 12: L. plantarum 2142

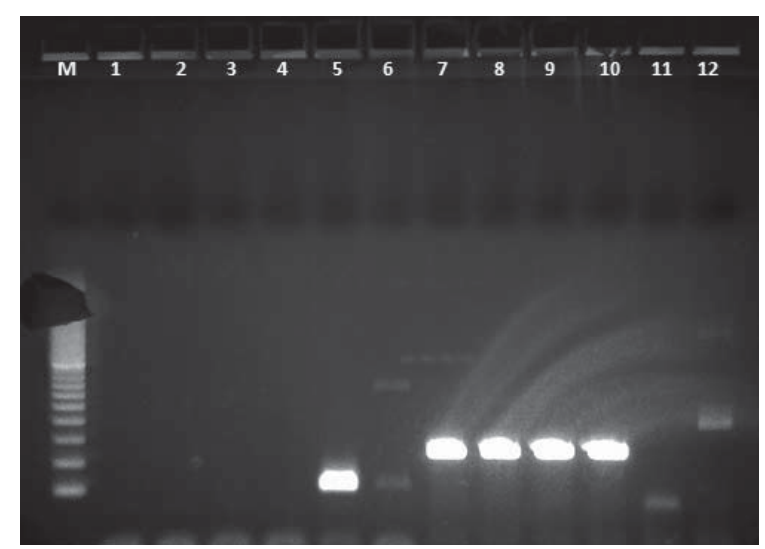

Fig. 3. Comparing the PCR results using chiA and chiFEM primer pairs: M: DNA marker; 1-4: S. marcescens strains; 5: L. acidophilus N2; 6: L. delbrueckii subsp. bulgaricus B397; 7-10: S. marcescens strains; 11: L. acidophilus N2; 12: L. delbrueckii subsp. bulgaricus B397; 1-6: chiA primer; 7-12: chiFEM primer Acta Alimentaria 49, 2020 


\subsection{Identification of chitinases and chitinase homologous proteins by immunoblot} and HPLC techniques

The protein composition of $L$. rhamnosus $\mathrm{GG}$ as no chitinase coding gene possessing negative control, five selected Lactobacillus strains, and S. marcescens were analysed by SDS-PAGE (Fig. 4A). After electrophoresis, the proteins were subjected to Western blotting, and the chitinases were identified with Thamchi peptide-specific rabbit IgG serum. The chitinase of S. marcescens showed antigenic response at approximately $30 \mathrm{kDa}$ (Fig. 4B). No chitinase bands were detected in LAB samples.

$$
\text { A }
$$

Mw (kDa)

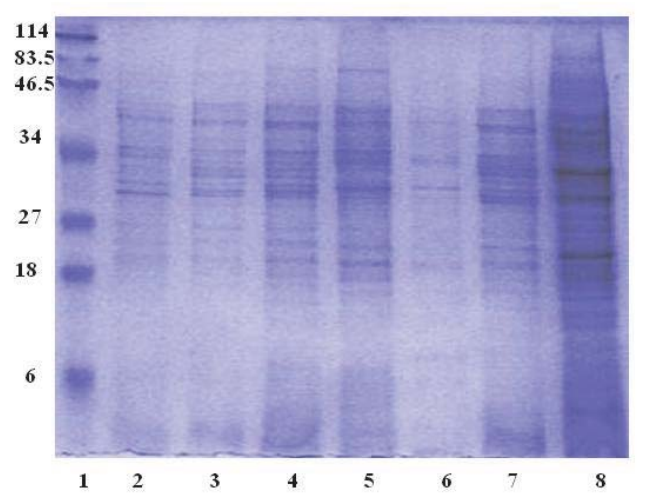

B

Mw (kDa)

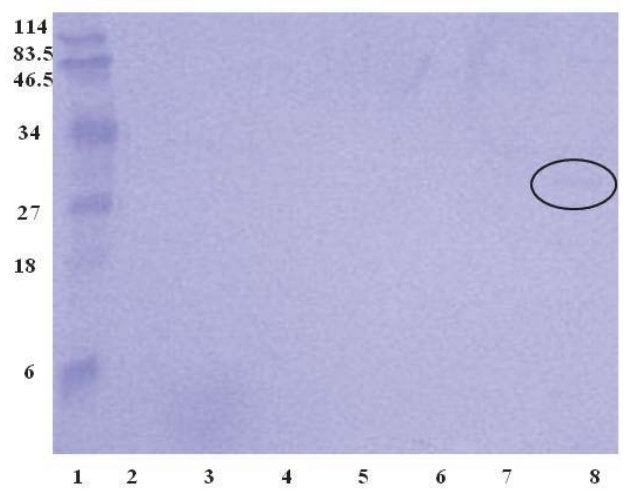

Fig. 4. SDS-PAGE (A) and Western blot (B) (using Thamchi peptide-specific rabbit IgG serum) of bacterial samples: 1: MW; 2: L. rhamnosus GG (negative control); 3: L. acidophilus N2; 4: L. delbrueckii subsp. bulgaricus B397; 5: Lactobacillus sp. 2231; 6: L. sakei subsp. sakei 2471; 7: L. buchneri 1145; 8: S. marcescens (control)

We determined the chromatographic profile of S. marcescens and L. acidophilus N2. Chitinases from Streptomyces griseus (Sigma) were loaded on the C18 column, and the proteins were eluted with an increasing acetonitrile gradient (Fig. 5A). The proteins of supernatants of $S$. marcescens and $L$. acidophilus $\mathrm{N} 2$ were concentrated by ammoniumsulphate precipitation and redissolved in solvent A. The protein profiles of S. marcescens (Fig. 5B) and L. acidophilus N2 (Fig. 5C) presented the same peaks that were observed on the chromatogram of purified chitinases at the detection time 22.6 and $27 \mathrm{~min}$. 


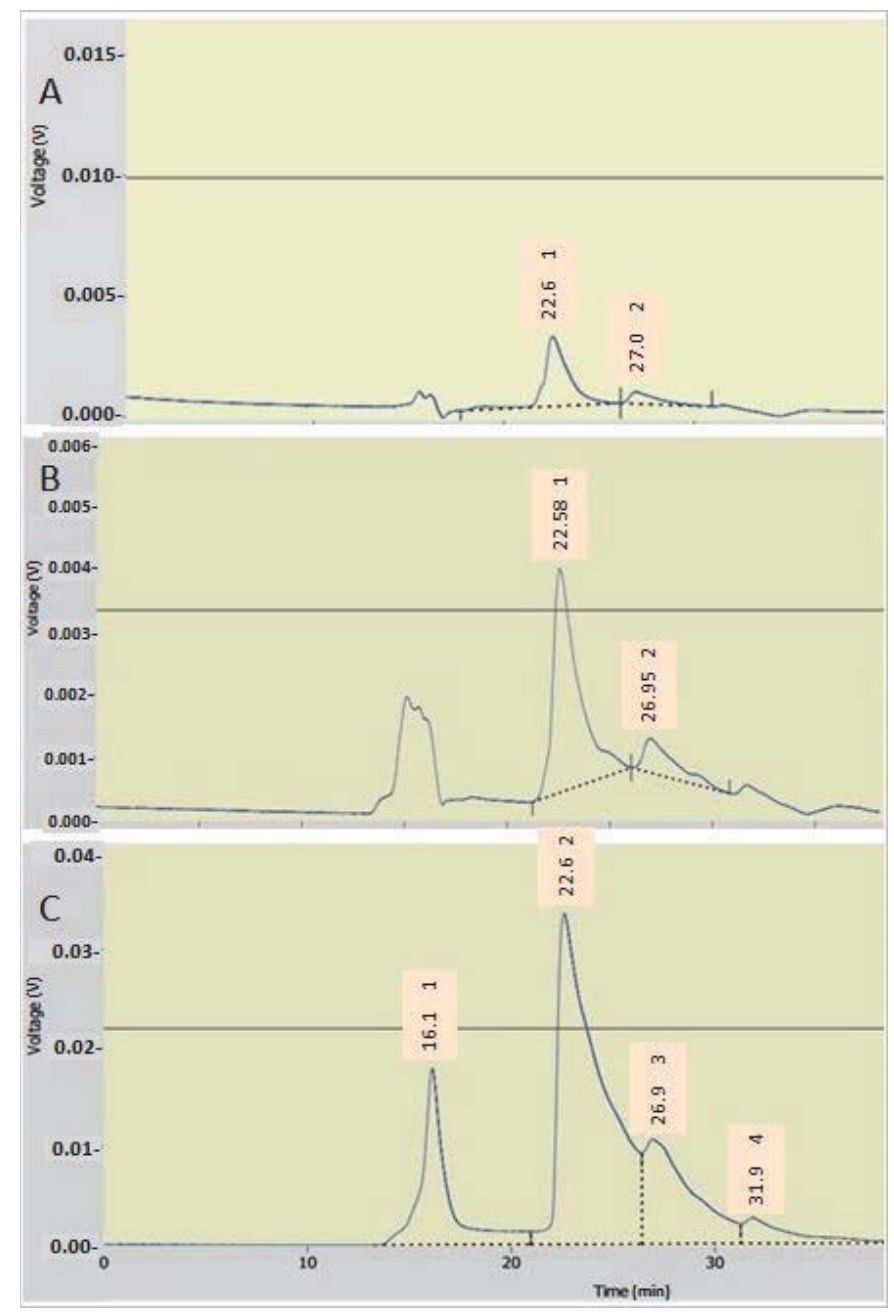

Fig. 5. HPLC (C18) profile for the chitinases from Streptomyces griseus (A); the supernatant of S. marcescens (B) and the supernatant of L. acidophilus N2 (C)

\subsection{Surface-associated proteins from selected Lactobacillus strains}

CBP proteins can play an important role in the degradation of chitin by being able to bind directly to chitin. In the case of $L$. plantarum, extracellular proteins have been identified (SANCHEZ et al., 2011) that are capable of binding to mucin in vitro, and some of them have been found to contain a chitin-binding domain. The extracted surface-associated proteins from the PCR-selected Lactobacillus strains were analysed by SDS-PAGE (Fig. 6). The examined strains showed slightly different protein profiles. In case of each tested strain an intensive protein band was found at $40 \mathrm{kDa}$, where chitin-binding protein was identified according to the results of BECK and co-workers (2009) as well. 


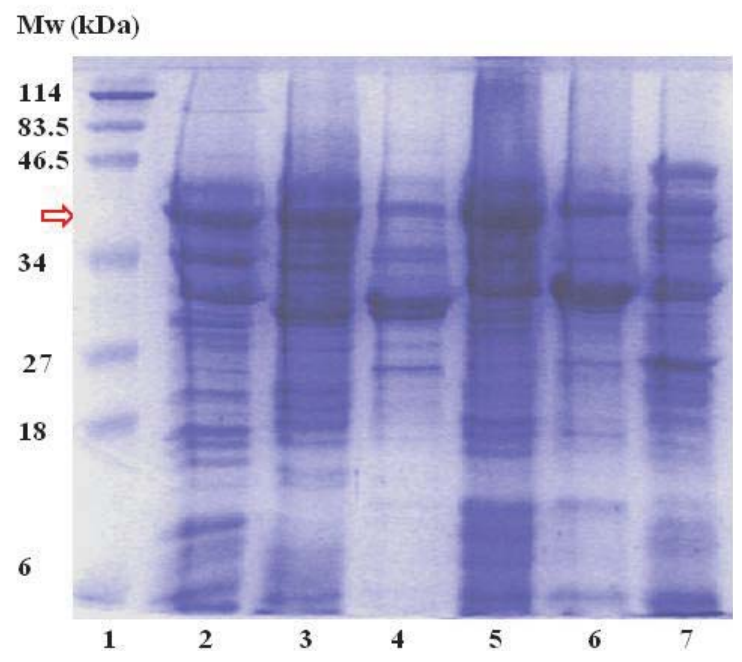

Fig. 6. SDS-PAGE of surface-associated proteins from Lactobacillus strains: 1: MW; 2: L. plantarum 299v; 3: L. acidophilus N2; 4: L. delbrueckii subsp. bulgaricus B397; 5: L. buchneri 1145; 6: Lactobacillus sp. 2231; 7: L. sakei subsp. sakei 2471

\subsection{Chitin-binding proteins from selected Lactobacillus strains}

After proliferation of the examined Lactobacillus strains, the binding of the supernatant proteins to colloidal chitin was studied by SDS-PAGE separation (Fig. 7). The detectable protein bands were obtained at 29-33 kDa molecular weight range (N2, 299v, 1145, 2231, and 397) - except in the case of 2471 strain - and at 40-43 kDa.

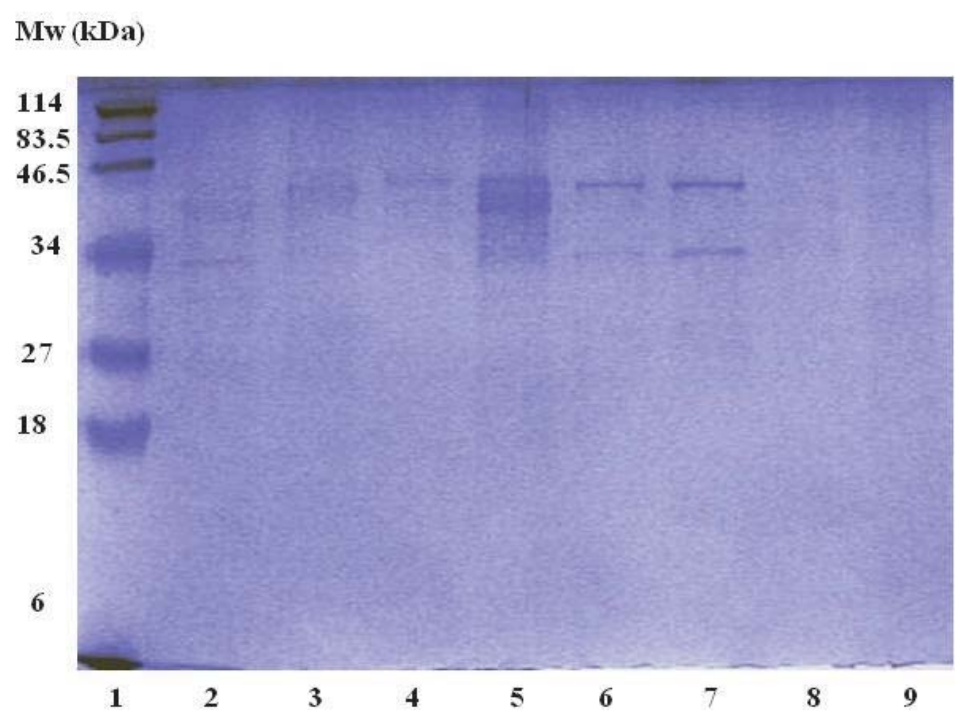

Fig. 7. SDS-PAGE of chitin-binding proteins from the supernatant of Lactobacillus strains: 1: MW; 2: L. plantarum 299v; 3: Lactobacillus sp. 2231; 4: L. sakei subsp. sakei 2471; 5: L. buchneri 1145;

6: L. delbrueckii subsp. bulgaricus B397; 7: L. acidophilus N2; 8: MRS; 9: S. marcescens 


\subsection{Chitinase activity assays}

2.5.1. Microbiological method. None of the tested Lactobacillus strains showed clearing zones, which means they did not hidrolyse the chitin substrate in the BCM media, either in case of the crude or the colloidal chitin. To ensure the optimal medium conditions, the assay was done on MRS, the specific media for lactobacilli, where the glucose was substituted with colloidal chitin, since in case of some bacteria glucose inhibits the transcriptions of chitinase gene (BERINI et al., 2018). We have tried to induce the chitinase activity with the changing of different environmental parameters, since the expression of the chitinolytic activity in bacteria is influenced by several parameters, eg. concentration of the chitin substrate, presence of sugars, the nitrogen source, the temperature and time of the incubation, and the $\mathrm{pH}$ of the medium (KARTHIK et al., 2017). For this reason the induction effect of the concentration of chitin, glucose, pepton, yeast extract, ammonium sulphate, ammonium chloride and the temperature and $\mathrm{pH}$ were investigated on the expression of chitinase activity. Nevertheless, chitinolytic activity was not detected in any chitin containing medium or due to changes in the environmental parameters.

2.5.2. Chitin azure chitinase assay. Chitin azure chitinase assay was performed to measure the chitinase activity of the positive control S. marcescens and the selected Lactobacillus buchneri L1145 holding chitinase coding gene. One enzyme unit was defined as a change in the optical density at $570 \mathrm{~nm}\left(\Delta \mathrm{OD}_{570}\right)$ of $1.0 \mathrm{in} 24 \mathrm{~h}$. The calculated value of the enzyme activity of $S$. marcescens was $0.68 \mathrm{U}$. No chitinase activity was detected for Lactobacillus buchneri L1145.

Despite that chitinase coding gene, proteins similar to the bacterial chitinases in molecular weight and separation properties, and chitin biding proteins were detected from five Lactobacillus strains, neither the microbial method, nor the chitin azure assay showed any chitinolytic activity of these strains. Numerous organisms including plants, invertebrates, and higher animals express genes encoding so called chitinase-like proteins (they are called also chi-lectins), which show homology to family 18 chitinases, but lack enzymatic, catalytic activity, however, have the ability to bind chitin (ShI \& PaSkewitz, 2004; AdRangi \& FARAMARZI, 2013). Chitinase-like proteins are structurally homologous to chitinases, so their dissimilarity can be observed only by the presence or absence of their catalytic activity. According to our results, the proteins produced by the strains possessing the chitinase coding gene could be the members of chitinase-like proteins. However, these chitinase-like proteins lack the essential catalytic activity, they have several, among others regulatory functions, but their role in the bacteria, especially in lactobacilli is still not completely known.

\section{Conclusions}

The majority of the large numbers of reports on antimicrobial activity of LAB have focused on antibacterial effects, while studies on antifungal effects are few (MAGNUSSON et al. 2003). Many bacteria have been shown to produce chitinases, and although most appear to be under tight control of expression, the mechanisms involved in the control of expression are poorly understood. In this study, we have selected Lactobacillus strains (L. acidophilus N2, L. delbrueckii subsp. bulgaricus B397, L. sp. 2231, L. sakei subsp. sakei 2471, and L. buchneri 1145 ), which are suitable for producing chitin-degrading enzymes according their genetic 
information. Proteins with similar molecular weight and separation properties like bacterial chitinases were detected from the selected strains, which possess also chitin binding property, nevertheless they were inactive, lacking the chitinolytic activity. These properties presume that the purified proteins are the members of chitinase-like proteins, which show homology to chitinases, but they are devoid of chitin degradation activity. The chitinase-like proteins from mammals (YKL-40), insects (IDGF3), and even from plants (CTL1) have been thoroughly investigated recently, but the information on bacterial chitinase-like proteins is scarce. However,studies on the chitinase of Lactobacillus strains are also rare. According to our best knowledge, this is the first report on the presence of chitinase-like proteins in Lactobacillus.

This project (TÉT_16_CN-2016-0004) has been implemented with the support provided from the National Research, Development and Innovation Fund of Hungary, financed under the TÉT_16_CN funding scheme, and supported by the National Key R\&D Program of China (2016YFE0130600).

\section{References}

Adrangi, S. \& FARAmarzi, M.A. (2013): From bacteria to human: A journey into the world of chitinases. Biotechnol. Adv., 31, 1786-1795.

Beck, H.C., Madsen, S.M., Glentino, J., Petersen, J., Israelsen, H., ... \& Hansen, A.M. (2009): Proteomic analysis of cell surface-associated proteins from probiotoc Lactobacillus plantarum. FEMS Microbiol Lett., 297(1), 61-66.

BeHERA, S.S., RAY, R.C. \& ZdoleC, N. (2018): Lactobacillus plantarum with functional properties: An approach to increase safety and shelf-life of fermented foods. Biomed. Res. Int., 2018: 9361614.

Berini, F., Katz, C., Gruzdev, N., Casartelli, M., Tettamanti, G. \& Marinelli, F. (2018): Microbial and viral chitinases: Attractive biopesticides for integrated pest management. Biotechnol Adv., 36, 818-838.

Inoue, H., Ozaki, N. \& Nagasawa, H. (2001): Purification and structural determination of phosphorylated peptide with anti-calcification and chitin-binding activities in the exoskeleton of the crayfish, Procambarus clarkii. Biosci. Biotech. Bioch., 65(8), 1840-1848.

Karthik, N., Binod, P. \& Pandey, A. (2017): Chitinases, -in: Pandey, A., Negi, S. \& Soccol, C.R. (Eds) Current developments in biotechnology and bioengineering: Production, isolation and purification of industrial products. Elsevier. pp. 335-368. http://dx.doi.org/10.1016/B978-0-444-63662-1.00015-4

Le Bourse, D., Conreux, A., Villaume, S., Lameiras, P., Nuzillard, J.M. \& Jeandet, P. (2011): Quantification of chitinase and thaumatin-like proteins in grape juices and wines. Anal. Bioanal. Chem., 401(5), 1541-1549.

Leisner, J.J., Vogensen, F.K., Kollmann, J., Aideh, B., Vandamme, P., ... \& Ingmer, H. (2008): $\alpha$-Chitinase activity among lactic acid bacteria. Syst. Appl. Microbiol., 31, 151-156.

LiU, C.L., LAN, C.Y., Fu, C.C. \& JuANG, R.S. (2014): Production of hexaoligochitin from colloidal chitin using a chitinase from Aeromonas schubertii. Int. J. Biol. Macromol., 69, 59-63.

Magnusson, J., Ström, K., Roos, S., Sjörgen, J. \& Schnürer, J. (2003): Broad and complex antifugal activity among environmental isolates of lactic acid bacteria. FEMS Microbiol. Lett., 219, 129-135.

Manjeet, K., Purushotham, P., Neeraja, C. \& Podile, A.R. (2013): Bacterial chitin binding proteins show differential substrate binding and synergy with chitinases. Microbiol. Res., 168, 461-468.

Ramaiah, N., Hill, R.T., Chun, J., Ravel, J., Matte, M.H., ... \& Colwell, R.R. (2000): Use of a chiA probe for detection of chitinase genes in bacteria from the Chesapeake Bay. FEMS Microbiol. Ecol., 34, 63-71.

Ramos, B., Ferreira, V., Brandao, T.R.S., Teixeira, P. \& Silva, C.L.M: (2016): Antilisterial active compound from lactic acid bacteria present on fresh iceberg lettuce. Acta Alimentaria, 45(3), 416-426.

Sanchez, B., González-Tejedo, C., Ruas-Madiedo, P., Urdaci, M.C. \& Margolles, A. (2011): Lactobacillus plantarum extracellular chitin-binding protein and its role in the interaction between chitin, Caco-2 cells, and mucin. Appl. Environ. Microb., 77(3), 1123-1126. 


\section{HORVÁTH-SZANICS et al: CHITINASE AND CHITINOLYTIC ACTIVITY OF LAB STRAINS}

ShI, L. \& Paskewitz, S.M. (2004): Identification and molecular characterization of two immune-responsive chitinase-like proteins from Anopheles gambiae. Insect Mol. Biol., 13, 387-398.

Singh, A.K. \& Ramesh, A. (2008): Succession of dominant and antagonistic lactic acid bacteria infermented cucumber: Insights from a PCR-based approach. Food Microbiol., 25, 278-287.

Thompson, S.E., Smith, M., Wilkinson, M.C. \& Peek, K. (2001): Identification and characterization of a chitinase antigen from Pseudomonas aeruginosa strain 385. Appl. Environ. Microb., 67(9), 4001-4008.

Open Access statement. This is an open-access article distributed under the terms of the Creative Commons Attribution 4.0 International License (https://creativecommons.org/licenses/by/4.0/), which permits unrestricted use, distribution, and reproduction in any medium, provided the original author and source are credited, a link to the CC License is provided, and changes - if any - are indicated. (SID_1)

Acta Alimentaria 49, 2020 